\title{
Potentially Useful Biomarkers for Obesity
}

\author{
Violeta-Elena SIMION*, Adriana AMFIM, Monica PARVU, Silvia SOESCU \\ Faculty of Veterinary Medicine, Spiru Haret University, \\ 256 Basarabia Ave., 30352 Bucharest, Romania, \\ simion.violeta.elena@gmail.com
}

Bulletin UASVM Veterinary Medicine 73(2) / 2016,

Print ISSN 1843-5270; Electronic ISSN 1843-5378

DOI:10.15835/buasvmcn-vm: 12243

\begin{abstract}
The mechanism of obesity is a complex one, while in regulating feeding behavior there are other factors that act, among which the hypothalamic centers, the metabolic balance of the internal environment, information's digestive system, endocrine system or adipose tissue response. The study on a group of cats aimed to evaluate specific biochemical parameters of lipid metabolism - cholesterol, triglicerides, LDL, HDL, including a parameter less assessed in medical veterinary practice - apolipoprotein B (Apo-B). Increased levels of this parameter are found in disorders such as obesity, hiperlipoproteinemia, nephrotic syndrome, diabetes etc. The results revealed significant disorders of lipid metabolism with predisposition to obesity, hyperlipidemia and cardiovascular disease.
\end{abstract}

Keywords: pets obesity, apolipoproteins, lipid profiling

\section{INTRODUCTION}

Genetic differences play an important role in the development of obesity but environmental factors are also very important (Elliott and Johnson, 2007). There are very few studies that refer to Apo-B and pets - according to the literature it has been shown that dogs exhibit no cholesterol ester transfer protein (CETP) activity in vitro, in contrast to humans (Bailhache et al., 2004) and both cats and dogs have hormones and adipogene factors similar with other species, being affected in a similar way through obesity (Blum et al., 2008). Apolipoproteins (Apo-A, Apo-B, Apo-E) represent the proteic component of lipoproteins (LDL, HDL, VLDL); these confer structural integrity for the central hydrophobic lipids and have a role in the transport of lipids from intestinal level to the liver and the organism's cells; HDL are the predominant lipoproteins in plasma of dogs and cats (Watson, 1996) and play an important role in recognizing the receptors for lipoproteins and the regulation of certain enzimes from the lipoprotein metabolism (Sako et al., 2001, 2003). Other research was focalized towards identifying and understanding the molecular level interactions between nutrients and other bioactive substances from food and genome (Simopoulos, 1989).

\section{AIMS AND OBJECTIVES}

The research primarily aims at following the values of Apo-B markers in the blood, at a group of cats registered with a veterinary clinic in Bucharest, Romania. The objective is to highlight the values of some biochemical parameters specific to the lipidic profile and Apo-B, carried out to two years difference-2014 and 2016, at the investigated patients.

\section{MATERIALS AND METHODS}

Cases that have been investigated are 6 European feline aged between 3 to 9 years, castrated, with the obesity tred, monitored in the environment in which they grow, concomitently with the monitoring of changes in alimentation. The biochemical analyses were done on Analyser of dry biochemistry ARKRAY SPOTCHEM EZSP-4430 REFURBISHED. The biochemical analysis of urine was done on Analyser with strips Vielab U-11V West Medica. Apolipoprotein B was determined through the measurement technique 
Tab. 1. Case summaries with the biochemical analyses results performed in 2014 and 2016

\begin{tabular}{|c|c|c|c|c|c|c|c|c|c|c|}
\hline & Albumin & AST & ALT & Bilirubin & Glucose & Triglyceride & Cholesterol & LDL_col & HDL & Urea \\
\hline \multirow{10}{*}{ 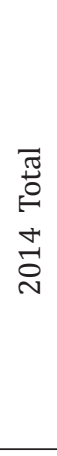 } & $\mathrm{N}$ & 6 & 6 & 6 & 6 & 6 & 6 & 6 & 6 & 6 \\
\hline & Mean & 2,9833 & 37,9167 & 61,6667 & 1,0000 & 112,1667 & 1,4667 & 206,6667 & 143,8333 & 35,3333 \\
\hline & Median & 3,0500 & 36,2500 & 62,5000 & ,6500 & 115,0000 & 1,4500 & 201,0000 & 151,5000 & 32,0000 \\
\hline & Sum & 17,90 & 227,50 & 370,00 & 6,00 & 673,00 & 8,80 & 1240,00 & 863,00 & 212,00 \\
\hline & Minimum & 2,30 & 18,00 & 29,00 &, 10 & 92,00 & 80 & 120,00 & 80,00 & 25,00 \\
\hline & Maximum & 3,50 & 60,00 & 80,00 & 3,00 & 130,00 & 2,10 & 290,00 & 170,00 & 55,00 \\
\hline & Range & 1,20 & 42,00 & 51,00 & 2,90 & 38,00 & 1,30 & 170,00 & 90,00 & 30,00 \\
\hline & Std. Deviation & ,41673 & 15,42212 & 18,42462 & 1,08628 & 15,77868 & ,43205 & 57,81234 & 33,64768 & 10,57670 \\
\hline & Variance &, 174 & 237,842 & 339,467 & 1,180 & 248,967 & ,187 & 3342,267 & 1132,167 & 111,867 \\
\hline & Std. Error of Mean & ,17013 & 6,29605 & 7,52182 & ,44347 & 6,44162 & ,17638 & 23,60179 & 13,73661 & 4,31792 \\
\hline \multirow{10}{*}{ 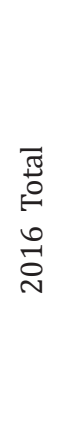 } & $\mathrm{N}$ & 6 & 6 & 6 & 6 & 6 & 6 & 6 & 6 & 6 \\
\hline & Mean & 3,0667 & 37,5833 & 59,1667 & 1,2333 & 121,0000 & 1,4583 & 208,5000 & 141,1667 & 39,0000 \\
\hline & Median & 3,1000 & 38,0000 & 53,0000 & ,8000 & 106,0000 & 1,3500 & 182,5000 & 137,5000 & 39,5000 \\
\hline & Sum & 18,40 & 225,50 & 355,00 & 7,40 & 726,00 & 8,75 & 1251,00 & 847,00 & 234,00 \\
\hline & Minimum & 2,60 & 12,00 & 38,00 &, 20 & 98,00 & 1,20 & 165,00 & 118,00 & 27,00 \\
\hline & Maximum & 3,50 & 68,00 & 90,00 & 4,10 & 178,00 & 1,90 & 283,00 & 175,00 & 58,00 \\
\hline & Range & ,90 & 56,00 & 52,00 & 3,90 & 80,00 & ,70 & 118,00 & 57,00 & 31,00 \\
\hline & Std. Deviation & ,36148 & 20,45585 & 18,44361 & 1,42782 & 31,59114 & 28003 & 53,15919 & 22,74570 & 11,31371 \\
\hline & Variance &, 131 & 418,442 & 340,167 & 2,039 & 998,000 &, 078 & 2825,900 & 517,367 & 128,000 \\
\hline & Std. Error of Mean & 14757 & 8,35106 & 7,52957 &, 58290 & 12,89703 & 11432 & 21,70215 & 9,28589 & 4,61880 \\
\hline
\end{tabular}

using imunoturbidimetric kits (334nm, 340nm, $365 \mathrm{~nm})$.

\section{RESULTS AND DISCUSSION}

Apo-B is the principal apolipoprotein from chylomicrons and LDL (proteins with low density) and the higher levels of this marker appear in changes of the lipidic metabolism which entail excessive lipidic deposits (over-weight, obesity, atherosclerosis, vascular and cardiac diseases). In the following (Tab.1) we present the results obtained from the case studies investigated.

Firstly, from Table 1 it can be observed that all parameters have 6 determinations for each of 2014 and 2016, while ApoB was only determined for 2016. Thus, we are able to make a direct comparison over time for all but one of the parameters determined. When looking at the Mean and Median, it can be observed that Albumin, AST, Bilirubin, Glucose, Urea and Creatinine display values within the reference limits for both years. However, the generally high Standard deviation and Range suggest that among the 6 cases studied there are values above and well below the reference. On the other hand, ALT, Triglyceride, Cholesterol, LDL col, HDL and
ApoB (only for 2016) have values either in one or both years that exceed the reference limits. In the case of ALT we can see a clear improvement as the values return within the reference in 2016. For Triglyceride, Cholesterol and LDL col the values are above the reference limit in both years, although in 2016 the Median is significantly lower than the mean which suggests that within that year some of the cases have values within the reference bracket, while the rest compensate and lead to a Mean slightly over the limit. In spite that the HDL Mean and Median values in 2016 are also outside the reference limit, the values are very close (39 and 39.5 respectively) which suggests a clear improvement in this parameter and a return towards the reference.

\section{CONCLUSIONS}

In this studies, we can observe a tendency for parameters to improve and return to the reference limit in 2016. However, since the cases are not a random sample, most of the changes can be explained by external factors to these parameters such as stress factors, type of food and diet or physical state of the animal, factors which are largely influenced by the pet owners themselves. 


\section{REFERENCES}

1. Bailhache E, Briand F, Nguyen P, Krempf M, Magot T, Ouguerram K (2004). Metabolism of cholesterol ester of apolipoprotein B100-containing lipoproteins in dogs: evidence for disregarding cholesterol ester transfer. European Journal Of Clinical Investigation 34(8): 527-534;http://search.ebscohost.com/login.aspx?direct $=$ true $\& \mathrm{db}=\mathrm{a} 9 \mathrm{~h} \& \mathrm{AN}=14069382 \&$ site $=$ ehost-live

2. Blum K, Chen TJ, Williams L, Chen ALC, Downs WB, Waite RL, Huntington T, Sims S, Prihoda T, Rhoads P, Reinking J, Braverman D, Kerner M, Blum SH, Quirk B, Braverman ER (2008). A short term pilot open label study to evaluate efficacy and safety of LG839, a customized DNA directed nutraceutical in obesity: Exploring Nutrigenomics, Gene Therapy and Molecular Biology 12:371-382

3. Elliott RM, Johnson IT (2007). Nutrigenomic approaches for obesity research. Obesity Reviews. Vol.8(s1):77-81.
4. Sako T, Uchida E, Kagawa Y, Hirayama K, Takashi T, Nakade T, Niiyama M, Izumisawa Y, Tanizama H (2001). Immunohistochemical Detection of Apolipoprotein B-100 and Immunoglobulins (IgA, IgM, IgG) in the Splenic Arteries of Aging Dogs. Vet Pathol 38(4):407-13.

5. Sako T, Uchida E, Kagawa $\mathrm{Y}$, Hirayama K, Nakade $\mathrm{T}$, Taniyama H (2003). Immunohistochemical Detection of Apolipoprotein A-I and B-100 in Canine Atherosclerotic Lesions. Vet Pathol 40(3):328-31.

6. Simopoulos AP (1989). Genetic variation and nutrition - Proceedings of the First International Conference on Genetic Variation and Nutrition, Washington, D.C, June 22-23, page 2 -89

7. Watson T.,D.,G. (1996). Lipoprotein metabolism in dogs and cats. Comparative Haematology Int 6(1):17-23. 